\title{
Evaluation of Snowboard Deck through Physiological Analysis: Blood Lactate Concentration
}

\author{
Sun Hur' ${ }^{1}$ Jinho Back ${ }^{2 *}$ and Prabhat Pathak ${ }^{3}$ \\ 'Division of Sport Science, Kangwon National University, Chuncheon, Korea; letssunny@kangwon.ac.kr \\ 2Department of Leisure Sports, Kangwon National University, Samcheock, Korea; jhback@kangwon.ac.kr \\ 32Department of Physical Education, Seoul National University, Seoul Korea; prabhat.pathak82@gmail.com
}

\begin{abstract}
Objectives: With the need for development of domestic sports products in Korea, this study proposed to present a technical evaluation to verify effects of prototype decks on physiological characteristics. Methods/Statistical Analysis: Five slope style snowboarders were tested in an advanced slope style course which was $420 \mathrm{~m}$ in length with an average pitch of $20^{\circ}$ to maximum pitch of $30^{\circ}$. Double blind test was performed on prototype decks of 1st edition (B5) and 2nd edition (B1, B2, B3). A comparative physiological analysis of blood lactate concentration level while snowboarding on the course with different decks was analyzed. Findings: There was a statistically significant difference observed among different prototype decks $(\mathrm{p}<.05)$. The results of the post hoc test showed higher blood lactate concentration in B5, B2, B3 than B1 deck. Furthermore, significant difference was observed in the time period of accumulation $(\mathrm{p}<.01)$. When comparing difference in percent change to the resting state, 32.07\% increment was observed in B1, B2 and B3 decks than B5. After exercise, B1 increased by $49.82 \%$, B3 increased by $18.45 \%$ than B5, while B2 decreased by $3.32 \%$ than B5. According to the result obtained from our study, the lactate level of subjects while riding on the 2nd edition B3 deck was found to be most appropriate than 1st edition B5 prototype. Applications / Improvement: The results and the method from the study can be further applied to set a standard for physiological basis of performance analysis for various sporting equipment.
\end{abstract}

Keywords: Performance Analysis,Slope Style, Winter Sports

\section{Introduction}

The market of winter sport equipment has been a continuous rising. Among different winter sports, snowboard was first started in United States during the 1960s and commercialized from the 70s. Despite having a short history, snowboarding is now being enjoyed by millions of people around the world. Similarly, the snowboarder population in Korea in 2010, exceeded more than 6 million and has been in gradually rising and the imported goods accounted for most of the equipment and supplies in the markett?

However, the imported goods are customized based on the physique of western players, which urges a need for development of customized equipment especially for
Korean players. Furthermore, it is necessary for Korea to develop the competitiveness of domestic product with the use of technology and contribute to the development of winter sports industry as the host of the upcoming 2018 Winter Olympics. However, there are no verification system or standard to evaluate snowboarding equipment except the mechanical analysis while, these snowboarding equipment should be designed to be safe and durable even in a harsh sub-zero environmente,

The test of blood lactate concentration level in an actual field can be an important indicator to determine the degree of fatigue and injury. Therefore, the purpose of the study is to present a technical evaluation data to verify effect of prototype decks on physiological characteristics i.e. the blood lactate concentration by performing a comparative analysis among snowboarders.

*Author for correspondence 


\section{Methods}

\subsection{Subjects}

The subject of the present study were five slope-style snowboarders (age: $30.00 \pm 5.48$, height: 172.60 \pm 1.52 , weight: $63.40 \pm 4.72$, experience: $5.80 \pm 2.49$ ) who were registered in the Korean Snowboard Association. Prior to the test, the experimental motive, procedure and possible risks were communicated verbally and in writing to the participants. In addition, we explained to subjects the data processing anonymity and the disadvantage due to the absence of the studies and the participants only who fully understand and who were willing to participate voluntarily signed the experiment consent form.

\subsection{Experimental Design}

The test took place in the advanced slope-style course at "w" snow park, Kangwondo, Korea. The experimental slope was $420 \mathrm{~m}$ in length with an average pitch of $20^{\circ}$ to maximum pitch of $30^{\circ}$. The experiment was carried out in the weather with many clouds, the day- time average temperature was $9.5^{\circ} \mathrm{C}$, with wind direction in north-east direction, wind speed of $2.6 \mathrm{~m} / \mathrm{sec}$ and humidity level of 63\% (Figure 1).

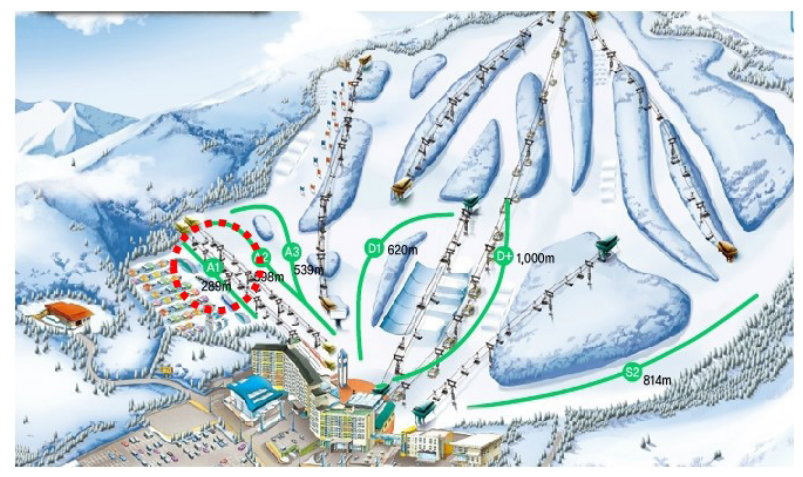

Figure 1. Experimental slope.

In order to analyze the effect of decks on performance, physiological analysis while snowboarding on the course was conducted with differently manufactured free-style rotating (twin-tip) decks of $160 \mathrm{~cm}$ length (one prototype snowboard deck from the $1^{\text {st }}$ edition (B5) and three prototype decks from $2^{\text {nd }}$ edition (B1, B2, B3)). Double blind test was performed to control the prejudice of researchers and subjects. Prior to the experiment, the participants were given sufficient time for pre-workout which consisted of stretching and warm-up runs. Then, for each deck, subjects performed three runs with 30 minutes' interval in between runs. In addition, after each run during the resting interval, survey consisting of both open-end and closed end questionnaire was conducted for each of the prototype decks.

\subsection{Blood Lactate Concentration}

Considering the environmental conditions, before the subjects took the lift, their blood samples were collected during the resting period in the base camp. In addition, the subjects were asked to snowboard to the course's end point without slowing down and their blood samples were carefully collected upon arrival without forming any bubbles from the fingertip using a heparinized capillary tube.

The collected blood samples were immediately packed in an icebox and were analyzed by injecting into a lactate analyzer (Biosen C-line sport, EKF Diagnostic, Germany). The difference between the blood lactate concentration during the rest and the post exercise was calculated as percentage for each of the differently manufactured decks ( $1^{\text {st }}$ edition: B5; $2^{\text {nd }}$ edition: B1, B2, B3) (Figure 2).
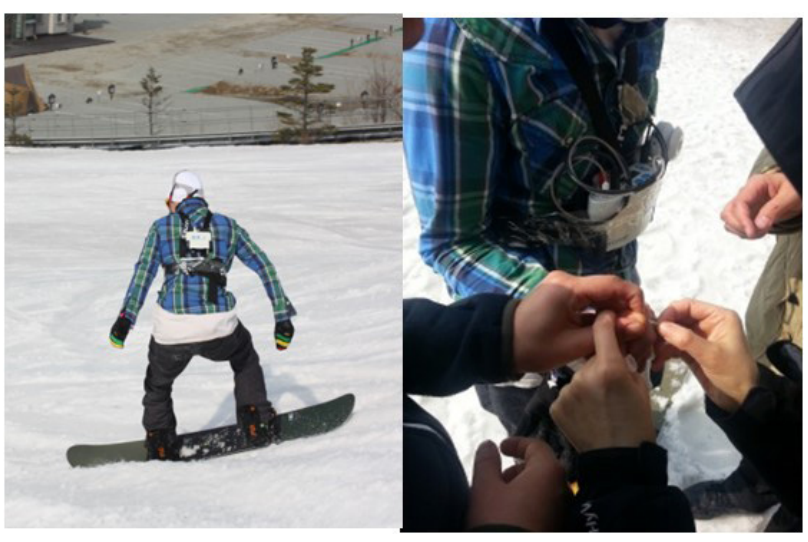

Figure 2. Experimental condition.

\subsection{Data Analysis}

Statistical analysis was performed with SPSS 20.0 (IBM, USA) using the mean and standard deviation. In order to analyze the effect of deck on blood lactate concentration, one-way ANOVA was used. In case of any significant difference, Duncan post hoc test and paired t-test was carried out with significance level set at $\alpha=0.05$. 


\section{Result}

The comparison of blood lactate concentration of different decks is presented in Table 1. and their difference expressed in percentage between rest and after exercise is shown in Figure 3.

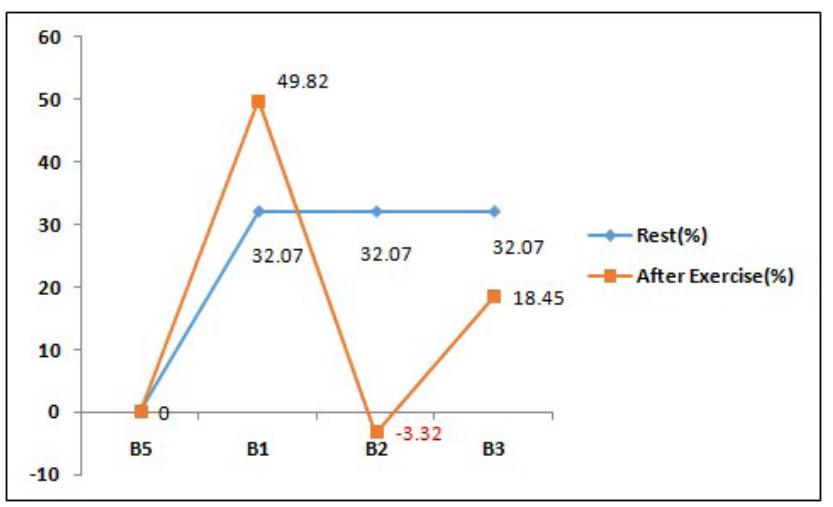

Figure 3. Change in lactate concentration.

There was a statistically significant difference observed among different prototype decks $(\mathrm{p}<.05)$. The results of the post-hoc test showed higher blood lactate concentration in B5, B2, B3 than B1 deck. Furthermore, significant difference was observed in the time period of accumulation $(\mathrm{p}<.01)$. However, there was no interaction effect between the types of decks and the time period of accumulation.

The results of the paired t-test showed statistical significant differences for B5 deck which increased by

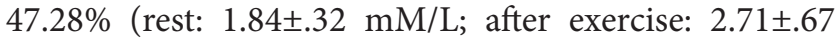
$\mathrm{mM} / \mathrm{L})(\mathrm{p}<.05)$. In case of B1. B2 and B3 decks, the increment in blood lactate concentration after the exercise were $67.08 \%, 7.82 \%$ and $32.10 \%$ respectively (Table 1 ).
When comparing to the resting state, $32.07 \%$ increment was observed in B1, B2 and B3 decks than B5. After exercise B1 increased by $49.82 \%$, B 3 increased by $18.45 \%$ than B5, while B2 decreased by $3.32 \%$ than B5 (Figure 3).

\section{Discussion}

From the point of view of training science, fatigue to some extent is required to strengthen the physiological capacity. However, excessive fatigue increases the risk of injury and reduces the exercise performance capacity ${ }^{1-6}$. The primary cause of fatigue due to movement can be exemplified by the depletion of energy resources, accumulation of fatigue substances in muscles (peripheral), disruption of homeostasis state, deficiencies in neural control. These changes in fatigue substances induces various changes depending on the exercise intensity, time, type, as well as environment? Therefore, to evaluate the physiological changes that the body exerts during an exercise session, "lactate" a fatigue substance is used as a baseline for performance enhancement, effectiveness of the training, adjustment of training level as well as to control the exercise intensity,

The results of blood lactate concentration in our study showed an immediate increase after the exercise compared to the resting level in all decks. $32.07 \%$ increment was observed in B1, B2 and B3 decks than B5 prototype deck. After exercise B1 increased by $49.82 \%$, B3 increased by $18.45 \%$ than B5, while B2 decreased by $3.32 \%$ than B5. In order to improve the elasticity and flexibility, the $1^{\text {st }}$ edition B5 deck was reinforced by using a side wall style wooden bamboo core deck with a carbon fiber pipe

Table 1. Comparison of blood lactate concentration while exercising with different decks

\begin{tabular}{|c|c|c|c|c|c|c|}
\hline \multirow{2}{*}{ Condition } & \multicolumn{4}{|c|}{ Snowboard Decks } & \multirow{2}{*}{ F } & \multirow{2}{*}{ Duncan } \\
\hline & B5 & B1 & B2 & B3 & & \\
\hline Rest & $1.84 \pm .32$ & $2.43 \pm .81$ & $2.43 \pm .81$ & $2.43 \pm .81$ & Deck $3.507^{\star}$ & $\mathrm{B} 5, \mathrm{~B} 2, \mathrm{~B} 3<\mathrm{B} 1$ \\
\hline After Exercise & $2.71 \pm .67$ & $4.06 \pm 1.74$ & $2.62 \pm .46$ & $3.21 \pm 1.06$ & Period $9.320^{\star *}$ & Rest $<$ after exercise \\
\hline $\begin{array}{l}\text { Pre-Post change } \\
(\%)\end{array}$ & 47.28 & 67.08 & 7.82 & 32.1 & Deckxperiod 1.246 & \\
\hline $\mathrm{t}$ & $-2.873^{\star}$ & -3.052 & -0.775 & -1.714 & & \\
\hline
\end{tabular}


inserted inside the core. Even though, the snowboarders evaluated the rides and the elasticity to be satisfactory, reinforcements for reducing the higher level of torsional and bending properties were required.

The $2^{\text {nd }}$ edition $\mathrm{B} 1$ prototype deck had the highest blood lactate accumulation level $(+49.82 \%)$ than any other decks which used a secondary reinforcement in order to reduce excessive torsion and bending generated in the previous model. In addition, a mount system was also developed that eased power transmission along the deck and facilitated turns. The rebounding phenomenon that arises at the latter part of the turn was evaluated to be low for the B1 prototype deck, which made the edge transition phase challenging ${ }^{10,1}$.

The $\mathrm{B} 2$ prototype deck was evaluated to be lighter in comparison to other decks and lacked edge grip which increased the tremors and effected the overall control of the deck. Hence, it was considered that the subjects were not able to increase the speed to their maximum capacity which could have resulted in lower level of lactate concentration $(-3.32 \%)$. The B3 prototype deck was evaluated to be in considerably stable state with reduced trembling during high speed. The subjects also reported that it facilitated rebounding naturally during the latter part of the turn and aided smooth transitions of the turn which could have resulted in lower lactate concentration level (+18.45\%).

\section{Conclusion}

The purpose of the study was to evaluate the effect of deck on blood lactate concentration level among slope-style snowboarder. According to the result obtained from our study, the lactate level of subjects while riding on the $2^{\text {nd }}$ edition B3 deck was found to be most appropriate than $1^{\text {st }}$ edition B5 prototype.

\section{References}

1. Jo Y, Baek JPJ. Ski/snowboard equipment import trend analysis. Trend Analysis of Import in Korea; 2014.

2. Arularasan A, Koteeswaran S. A study on influential evaluation of information hubs in social networks. Indian Journal of Science and Technology. 2016; 9(2):1-6.

3. Jhingan A, Kansal L. Performance evaluation for wavelet based OFDM system effected by CFO over Rayleigh channel. Indian Journal of Science and Technology. 2016; 9(5):1-6.

4. Langran M, Selvaraj S. Increased injury risk among firstday skiers, snowboarders, and skiboarders. The American Journal of Sports Medicine. 2004; 32(1):96-103.

5. Meyers MC. Downhill ski injuries in children and adolescents. Sports Medicine. 2007; 37(6):485-99.

6. Mienda BS, Shamsir MS, Salleh FM. In silico evaluation of the effect of PFL gene knockout on the production of D-lactate by Escherichia coli genome scale model using the optflux software platform. Indian Journal of Science and Technology. 2015; 8(2):172-7.

7. Thomas KS, Hynes H, Ingledew W. Influence of medium buffering capacity on inhibition of Saccharomyces cerevisiae growth by acetic and lactic acids. Applied and Environmental Microbiology. 2002; 68(4):1616-23.

8. Juel C. Effect of high-intensity intermittent training on lactate and $\mathrm{H}+$ release from human skeletal muscle. American Journal of Physiology-Endocrinology and Metabolism. 2004; 286(2):45-51.

9. Prabhu PV. Detection and evaluation of vascular wall elasticity using photoplethysmography signals in sinus rhythm subjects. Indian Journal of Science and Technology. 2016; 9(2):1-13.

10. Clifton P. Effects of temperature change on snowboard stiffness and camber properties. Sports Technology. 2009; 2(3-4):87-96.

11. Senthilkumaar P, Kalyanaraman V. Evolutionary gene expression of lactate dehydrogenase in water snakes Cerberus rhynchops and Xenochrophis piscator. Indian Journal of Science and Technology. 2010; 3(4):422-4. 